\title{
Knowledge, Attitude and Practice of Testicular Self-Examination among Male Undergraduate Students in a Tertiary Institution in Calabar, Cross River State Nigeria
}

\author{
Ella Regina Etita ${ }^{1 *}$, Edet Bamidele Olaide ${ }^{2}$, Opiah Margaret Mombel ${ }^{3}$, \\ Umana Affiong Edeyo \\ ${ }^{1,2.3,4}$ Department of Nursing Science, University of Calabar, Cross River State, Nigeria
}

\begin{abstract}
Testicular cancer (TC) is the most common cancer among young males. Morbidity and Mortality from TC is high in low income countries due to late presentation, poverty and scarce resources for management. Early detection of the disease leads to increased cure rate (96\%); early detection can be facilitated if men are knowledgeable and encouraged to practice TSE. A descriptive research with a sample of 255 undergraduate students was used for the study. The students were stratified based to their departments and level of study and convenient sampling was used to select the respondents. A self structured questionnaire was used for data collection. The results were analyzed using descriptive statistics, and results presented in tables and frequencies. Results show that 105(41.2\%) had good knowledge of TSE, 60(23.5\%) had moderate knowledge, 173(69.2\%) had a favourable attitude towards TSE. Despite the good knowledge and favorable attitude, majority of the respondents 138(54\%) did not practice TSE. Of those 117(46\%) that practiced TSE none did as recommended. Chi square $\left(x^{2}\right)$ analysis revealed significant relationship between undergraduate students knowledge of TSE and TSE practices $(P<0.05)$. The findings however revealed that knowledge was not commensurate with practice. Recommendations: University lecturers should create awareness and organize seminars about TSE for students. Teachers, health workers and significant others should encourage and supervise young men to perform TSE. Young men attending healthcare institutions for any reason should be given health education on TSE, accompanied with patient leaflets. TSE should be integrated in secondary school curriculum.
\end{abstract}

Key Words: Testicular self examination - testicular Cancer, knowledge, attitude, Practice, male undergraduate students, University of Calabar, Cross River State.

\section{Background}

Globally, Testicular Cancer (TC) accounts for approximately one percent of all cancers in men and has doubled in the last 40 years. The incidence varies considerably in different geographical areas, being highest in Scandinavia and Switzerland, intermediate in United States, Australia, and United Kingdom and lowest in Asia and Africa (American Cancer Society 2016, Ozturk, Unalan, and Guleser 2014). Although TC is relatively uncommon compared with other forms of cancer, the incidence has been on the increase in recent years in developing countries and has become one of the leading malignant diseases among males aged 18-50 years and the second highest cause of death in Africa, thereby constituting a serious health concern (Ajape, Babata and Abiula, 2010, Ingwu, Ohaeri, and Ezeude 2016). More than 90\% of patients are cured with surgery, radiotherapy, and chemotherapy alone or combination of them (Yetisyigit, Babacan, and Urun et al 2014). However, success in treatment depends on early detection and accuracy of disease diagnosis (Ozturk et al 2014, Atinel and Avei 2013, Alberts et al 2011). One major way to early detection and prevention of TC is the acquisition of accurate knowledge, positive attitude, accurate and regular practice of Testicular self examination (TSE).

Testicular self examination is a procedure by which a man checks the appearance as well as the consistency of his testicles. It is a simple painless procedure, and an important clinical tool for early detection of testicular cancer. According to the American Cancer Society (2016), TSE should take place during or immediately after a warm shower or bath, when the skin is warm, wet and soapy. The heat from the tub or shower will relax the scrotum and the skin will be softer and thinner, making it easier to feel a lump. Standing in front of a mirror, the exam should be performed gently looking for any swelling. Using both hands, the scrotum should be gently lifted so that the area underneath can be checked. The index and the middle fingers should be placed under each testicle, with the thumbs on top; each testicle should be rolled between fingers and thumbs to feel for lumps of any size (even as small as a grain of rice or a pea) particularly on the front or side of each testicle. Soreness or irregularities should be observed. It is normal for one testicle to be larger than the other and for them to hang at different levels; but the size should remain the same from one month to the next. The testes should be free from lumps, pain, irregularities and swelling. Any abnormality should be reported to a doctor as 
soon as possible because testicular cancer is highly curable if found early. Shalwani, Ramji, Ali, and Kuwaja (2010) and Ingwu et al (2016) reported a deficit in men's knowledege and need for change of attitude towards TSE practice, in particular among young populations such as university students. They asserted that less than one in five men regularly examined their testicles. This presents a major concern for the timely detection and treatment of testicular cancer.

Several studies seem to show low awareness and practice of TSE (Ingwu etal 2016, Onyiriuka and Imoebe 2013, Ramim, Mousavi, Rosatmnia, Bazyar, Ghanbari 2013, Ugboma and Aburoma 2011). Among the 540 secondary school boys studied in Benin City, nearly all (98.7\%) of the students never heard of TSE (Onyiriuka and Imoebe 2013). The authors suggested health education, using video presentations in schools to promote regular and accurate TSE. Ugboma and Aburoma (2011), assessment of the public awareness of testicular cancer and testicular self-examination in academic environments revealed that majority (88.6\%) had not heard of TC neither were they taught about TSE in school. Public health campaigns, health education for TSE, accompanied with leaflets were among their recommendations. Using 634 male University students to study testicular cancer awareness and testicular self-examination, the findings showed that although almost half of the students heard about TC, very few (5.9\%) knew about TSE (Ugurlu, Akkuzu, Karahan, Beder, Dogan, Okdems, \& Kav 2011),. Furthermore, Ingwu, et al (2016) study of 172 male medical students of the University of Nigeria, Enugu campus, revealed that $110(64.0 \%)$ had good knowledge of TSE, yet their knowledge was not proportional to the level of practice as $94(54.1 \%)$ had not performed TSE.

Some men feel incompetent to perform TSE and some see it as embarrassing, Ingwu et al (2016) and Muliira, Nalwanga, Muliira and Nakinga (2012) confirmed this assertion as they observed students feeling of incompetency towards TSE (54.1\%); feeling that TSE was embarrassing (98\%), and feeling that their risk for this disease was low. Ramim et al; (2013) reported that only about $10 \%$ of 330 young males in a medical science department, University in Iran had good attitude about performing TSE however, over 81\% showed poor selfefficacy. Out of 540 respondents Onyiriuka and Imoebe (2013) reported that only (47.2\%) had a positive intention to start performing TSE regularly after hearing of TSE. Prior to this, their attitude towards performing TSE was poor.

Mizie-Okoye, Belgam and Tella (2016), Onyiriuka and Imoebe (2013), Ugurlu et al (2011) reported low practices of TSE among various levels of students. Also Peltzer and Pengpid (2015) reported that among all male students from Bangladesh, Madagascar, Singapore, South Africa and Turkey, 86.4\% had never practiced TSE. According to Onyiriuka and Imoebe (2013), out of 540 secondary school boys in Benin City, only 7 students admitted examining their testicles. Furthermore Mizie-Okoye, Belgam and Tella (2016) reported that out of 256 senior secondary school students only 23 senior secondary school students (9.0\%) had ever performed TSE. A cross sectional study by Ozturk, Unalan, and Guelser (2014), on knowledge, attitude and practices of TC and TSE using 243 technicians and 235 healthy control subjects in Turkey: revealed that $80 \%$ of both groups did not practice TSE. Furthermore Ugurlu et al (2011) reported that repondents reason for not performing TSE was mostly "not having knowledge" (83.4\%) and not seen as important" (55.7\%).

For those who practiced TSE, compliance with recommended frequency (of at least ten times a year) and right method was low. Mulilra, Nalwanga, Mulilra and Nankunga (2012) confirmed that $80 \%$ of their respondents were not examining their testicles regularly. Vadaparampil (2009) also found out that of the 99 participants who met the inclusion criteria, $46 \%$ reported performing TSE 6 or more times in the previous year, while 52\% reported performing TSE less than 6 times as against the recommended number of at least 10 times a year (Otzurk et al 2014 ). Mizie-Okoye, Belgam and Tella (2016) reported that out of 256 senior secondary school students only 23 senior secondary school students (9.0\%) had ever performed TSE and only 8 of 23 (36.4\%) performed monthly as recommended. The findings suggest that, even in high- risk setting, TSE practices were low and irregular.

The Theory of Planned Behavior (TPB), proposed by Icek Ajzen in 1985; an extension of the Theory of Reasoned Action (TRA), by Martin Fishbein and Icek Ajzen in 1980 asserts that human behavior is guided by Behavioral, Normative, and Control beliefs. Behavioral beliefs produce favourable or unfavourable attitude toward the behavior; normative beliefs result in perceived social pressure or subjective norm; and control beliefs give rise to perceived behavioral control. In combination, attitude toward the behavior, subjective norm, and perceived behavioral control leads to formation of behavioral intention. The more favorable the attitude, subjective norm, and perceived control, the stronger a person's intention to perform the behavior in question. This theory predicts that male undergraduate students' are more likely to have an intention of performing TSE if they have positive attitudes about TSE, believe that subjective norms towards TSE are favourable and believe that they are able to perform TSE correctly.

Health education campaigns in developed and developing countries have dramatically increased awareness of breast and cervical cancers in women at risk, and have led to increased rates of early diagnosis and treatment, but the reverse has been the case for testicular cancer in men (Ugboma \& Abruoma 2011, Ogundipe \& Obinna, 2008). Also the studies of Guleser and Unalan (2010) and Ugurlu., Akkuzu, Karahan, Beder, Dogan, 
Okdems, \& Kav (2011) supports the notion that young males are misinformed about their risk of TC and do not understand the importance of periodic TSE. It also seems that men have poor health seeking behavior. Considering the fatality risk associated with complications of TC and the possibility of curative treatment when it is diagnosed early through TSE it important to examine young men's (undergraduate students) knowledge, attitude and practices. A few studies in this regard have been undertaken in some institutions in South South Nigeria, but none specifically in Cross River State with Undergraduate students in university of Calabar. Deliberately tailored health education by teachers and health care providers can address identified gaps. It is for this reason that the researcher is prompted to determine the knowledge, attitude and practice of TSE among male students of the University of Calabar in preparation to increase cancer awareness and prevention. This study will provide a base line for interventions and stimulate young men to start practicing TSE, help in the formulation appropriate health education intervention strategies and also serve as a reference material for other researchers.

Purpose of the Study The purpose of the study is to determine the level of knowledge, attitude towards, and level of practice of testicular self-examination among male undergraduate students in the University of Calabar (UNICAL), Calabar, and Cross River State. Specifically the study sought to: determine male undergraduate students' level of knowledge towards TSE, evaluate attitude towards testicular self-examination, determine the practice of testicular self-examination, and determine the frequency of practice of testicular self-examination among male undergraduate students of the University of Calabar.

\section{Materials And Methods}

Research Design The study was a cross sectional descriptive survey.

Research Setting: The area for this study was cross River State, which is one of the 36 states of the Federal Republic of Nigeria. Located in the south south region of the country the state has eighteen (18) Local Government Areas (LGAs) with Calabar as the headquarters. The study site is the University of Calabar also known as UNICAL, a Federal Institution located in Calabar Municipal Local Government Area of the state. UNICAL was a campus of the University of Nigeria (UNN) until 1975, when it was established with its motto "knowledge for service". The University currently has 12 faculties (with various departments) one of which is Faculty of Allied Medical Sciences comprised of four departments (nursing science, radiography, medical Laboratory Science and public health departments).

\section{Study Population}

The study population comprised of students from the faculty of allied medical sciences, (which was purposefully chosen) numbering 700. Students were stratified according to their departments namely; and into their levels of study, 1-5. A proportionate sample of 255 male undergraduate students was selected from each of the stratum using convenient sampling. Unwilling students and those not physically present were excluded.

\subsection{Instrument for Data Collection}

Data collection tool was self developed structured and pretested questionnaire designed to elicit information on the socio-demographic data of the respondents, knowledge, attitude towards and practice of TSE. A coefficient of correlation of the instrument was calculated using spearman's rank order correlation coefficient and the value obtained was 0.74 . Validated self-designed structured questionnaires were administered to the respondents by two research assistants and the researcher.

\section{Method of Data Analysis}

Data was analyzed using SPSS 16.0, interpreted using descriptive statistics: frequency tables, bar charts, and pie charts and converting same to percentages. Chi-square was used for the inferential statistics at $\mathrm{P}$ $<0.05$

\section{Ethical Consideration}

Ethical approval was obtained from the Health Research Ethical Committee (HREC) of University. Also self introduction was made to the dean of the faculty and respective heads of departments under the faculty. Informed consent was obtained from all respondents. 


\subsection{Socio-Demographic Data}

\section{Results}

Table 1: Demographic data of respondents $n=255$

\begin{tabular}{|l|l|l|}
\hline Characteristics & Frequency & Percentages \\
\hline Age in Years & & \\
\hline $18-27$ years & 203 & 79.6 \\
\hline $28-$ 37years & 39 & 15.3 \\
\hline $38-47$ years & 13 & 5.1 \\
\hline Marital Status & & \\
\hline Single & 217 & 85.1 \\
\hline Married & 26 & 10.2 \\
\hline Divorce & 12 & 4.7 \\
\hline Total & $\mathbf{2 5 5}$ & $\mathbf{1 0 0 . 0}$ \\
\hline Year of Study & & \\
\hline 100 level & 23 & 9.0 \\
\hline 200 level & 48 & 18.8 \\
\hline 300 level & 52 & 20.4 \\
\hline 400 level & 64 & 25.1 \\
\hline 500 level & 68 & 26.7 \\
\hline
\end{tabular}

The demographic data in table 1 showed that the most 203(79.6\%) respondents were between the age group of $18-27$ years. Majority $217(85.1 \%)$ were single. 68 (26.7\%) of the respondents were in 500 level, 23 $(9.0 \%)$ in 100 level, $52(20.4 \%)$ in 300 level, while $64(25.1 \%)$ were in 400 level.

Table 2: Knowledge Level of Testicular Self-Examination

\begin{tabular}{|l|l|l|}
\hline Levels of Knowledge & Frequency & Percentages \\
\hline Good Knowledge & 105 & 41.2 \\
\hline Moderate Knowledge & 60 & 23.5 \\
\hline Poor Knowledge & 90 & 35.3 \\
\hline Total & 255 & 100.0 \\
\hline
\end{tabular}

Out of the 255 respondents 105 (41.2\%) had good knowledge TSE, 60 (23.5\%) had moderate knowledge, while $90(35.3 \%)$ had poor knowledge.

\section{Attitude of male undergraduate students towards TSE}

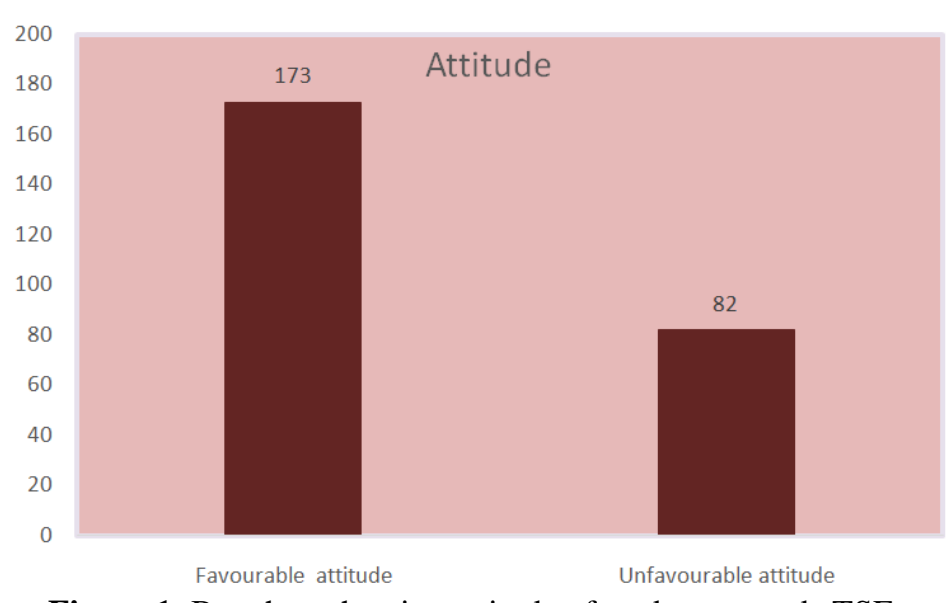

Figure 1: Bar chart showing attitude of student towards TSE

Among the 255 respondents used for the study, 173 (69.2\%) had a favourable attitude while $82(30.8 \%)$ had unfavourable attitude. 


\section{\#Practice of TSE among male undergraduate students}

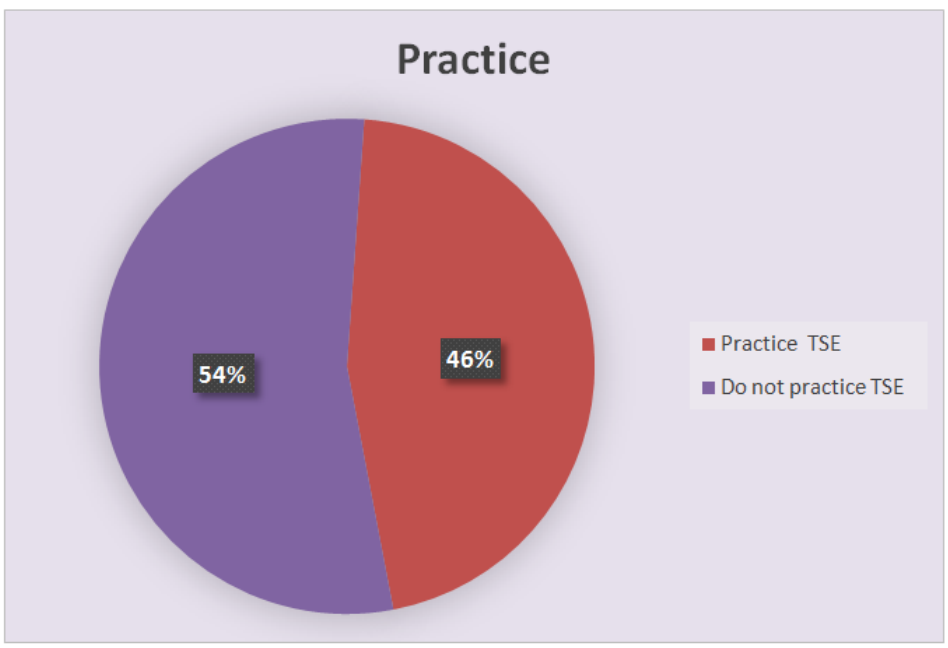

Figure 2: Pie chart showing the percentage of student who practice TSE.

Out of the 255 respondents, majority 138 (54\%) did not practice TSE while 117(46\%) did.

\section{Frequency of practice of TSE}

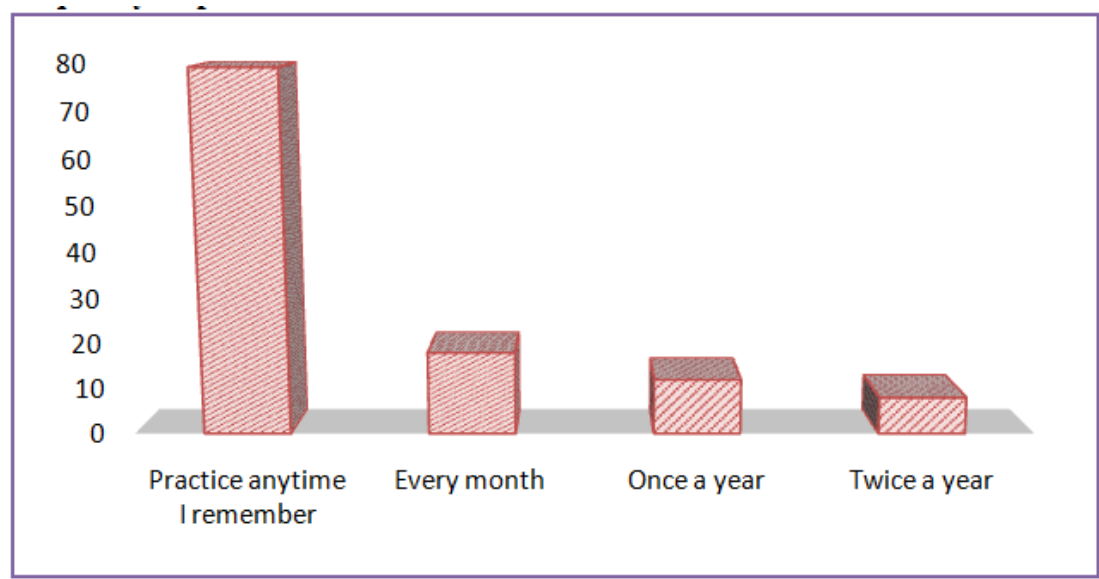

Figure 3: Bar chart showing frequency of practice of testicular self examination.

Among the 117 students who practiced TSE, 79(67.5\%) did so anytime they remembered, $18(15.3 \%)$ practiced every month, $12(10.2 \%)$ practiced once a year while $8(6.8 \%)$ practiced twice a year.

Table 3: Contingency Chi Square $\left(\mathrm{X}^{2}\right)$ analysis of the relationship between knowledge of and practice of testicular self-examination

\begin{tabular}{|l|l|l|c|}
\hline Levels of Knowledge & Practice & $\begin{array}{l}\text { Do not Total Calx } \\
\text { Practice }\end{array}$ & Df \\
\hline & & & \\
\hline Good Knowledge & $60(48.2)$ & $45(56.8) \quad 105$ & 5.99 \\
\hline Moderate Knowledge & $46(27.5)$ & $14(32.5) \quad 60 \quad 69.4$ & \\
\hline Poor Knowledge & $11(41.3)$ & $79(48.7) \quad 90$ & \\
\hline Total & 117 & 138 & \\
\hline Significant at 0.05, & $\mathrm{df}=2, \mathrm{X}^{2} \mathrm{Cal}$ & $6.94, \mathrm{X}^{2}$ tabulated 5.99 & \\
\hline
\end{tabular}

Using $\mathrm{X}^{2}$ statistical test analysis, the result in table 3 showed a statistical relationship between knowledge of TSE and the practice of TSE when the $X^{2}$ calculated of 6.94 was greater than $X^{2}$ tabulated of 5.99 at 0.05 of significance with 2 degrees of freedom. Meaning there is a significant relationship between knowledge of TSE and practice of TSE. 


\section{Discussions}

Majority of the respondents105 (41.2\%). in this study had good level knowledge of TSE though not proportional with the practice as $54 \%$ of the students did not practice TSE. The finding is however encouraging considering the fact that knowledge is always the first step towards motivation of desirable behavior. This finding agrees with that of Ingwu, et al (2016) study of 172 male medical students of the University of Nigeria, Enugu campus, which revealed that $110(64.0 \%)$ had good knowledge of TSE, but that knowledge was not proportional to the level of practice as $94(54.1 \%)$ had not performed TSE. Both findings might be attributed to the university environment that the respondents were associated with; it could be inferred that respondents directly obtained information from academic and social environment and from and peers. This finding was however at variance with the study of Onyiriuka and Imoebe (2013) where majority (98.7\%) of the respondents demonstrated very low knowledge of TSE. The difference in knowledge level may be due to variation in their institutional levels, that is, secondary school versus university.

The study revealed that, $173(69.2 \%)$ had a favourable attitude while $82(30.8 \%)$ had unfavourable attitude. This was not surprising since knowledge influences attitude; therefore measures that could lead to early detection of cancer were generally accepted. This finding however was contrary to the study of Ramim et al (2014), Muliira et al (2011) and Pelzer and Pengpid (2014) where respondents' portrayed poor attitude for TSE. The authors attributed their findings to the fact that respondents did not perceive TSE to be important, even if it was; not for their young age. Specifically, Ramim et al findings revealed that only about $10 \%$ of 330 young males in a medical sciences University in Iran had good attitude about performing TSE and over $81 \%$ showed poor efficacy. The differences in the findings of this study and that of Ramin et al could be associated with the cultural values and religious beliefs between the two countries (Nigeria and Iran) under the studies.

This study revealed low practices of TSE among male undergraduate students of the University of Calabar; even those that practiced did so irregularly and not as recommended. This finding could be associated with the fact that respondents did not perceive TSE to be important, even if it was; not for their young age, the youths' seems belief that they are not at risk of developing any ill health and that serious ailments like TC were more associated with advancement in age (Muliira et al 2011 and Pelzer and Pengpid 2014). This finding is further supported by that Ingwu et al, (2016), Onyiriuka and Amoeba's (2013) and Mizie-Okoye, et al (2016) that reported low practice of TSE despite the high level of knowledge. A chi-square value of 69.4 was obtained at $\mathrm{P}<$ 0.05 , showing a significant relationship between knowledge of TSE and practice of TSE. It therefore implies that good knowledge will increase practice of TSE and vice versa. However, this study has showed that despite the respondents' high knowledge and favorable attitude of TSE, majority of the respondents did not practice TSE. This could probably be attributed to the fact that the students did not have the confidence and competency to carry of TSE (Ingwu et al 2016). This gap in actual practice calls for concern among all stake holders considering the high risks of testicular cancer. It may necessary to undertake another study to ascertain the reasons for poor and low rate of practice despite the high knowledge and positive attitude.

\section{Conclusion.}

Male undergraduate students of the University of Calabar have good Knowledge and favorable attitude towardsTSE. However their knowledge and positive attitude did not translate into practice of TSE, possibly due toincompetency and lack of confidence to do so; and also to the fact respondents did not perceive TSE to beimportant, even if it was; not for their young age, because youths' seems belief that they are not at risk of developing serious ailments like TC, were which they perceive is associated with advancement in age. There isneed for encouragement and supervision from teachers and health workers and knowledgeable significant others. University lecturers should create awareness and organize seminars about TSE for students. TSE should be integrated in secondary school curriculum. TSE should be integrated in secondary school curriculum. Young men attending healthcare institutions for any reason should be given health education on TSE, accompanied by a patient leaflet.

\section{References}

[1]. Ajape, A. Babata, A. \& Aioli , O. (2010) Knowledge of prostate cancer among Native African urban population in Nigeria. Nigerian Journal of Hospice Medicine 20 (2) 94-96

[2]. Albers P. Albreeht W. Algaba F, et al (2011). European association of urology. EAU guide lines on testicular cancer: 2011 update. Eur Urol, 60, 304-319.

[3]. Altinel B, Aydin Avei I (2013) The knowledge beliefs and practices of university Students on testicular cancer and testicular self examination. TAF Prev Med Bull, 12,365-370

[4]. American Cancer Society (2016). Do I have Testicular Cancer? Retrieved on 21-9-2016 from m.cancer.org/cancer/testicularcancer/do-i-have-testicular-cancer.

[5]. Cancer Association of South Africa, CANSA (2016). Fact sheet on Testicular cancer. Retrieved on 7-10-2016 from http://www.health-res.com/EX107-3016/maleguduativesystem:jpg.

[6]. Garner I. D. (2011). A Q-methodological study of male attitude towards testicular cancer and testicular self-examination. Retrieved on 21-10-2016 from www.inquiriesjourmal.com 
[7]. Gulsner, G.N, \& Unalan, D. (2010) The Knowledge attitudes and behaviors of health services vocational students on testicular cancer and testicular self examination. European Journal of Oncology Nursing, 14(S1), S35.

[8]. Ingwu J. A., shaeri B., \& Ezeude A. G. (2016). Awareness and practice of Testicular self-examination among male medical students of University of Nigeria Enugu campus, South-East Nigeria. IOSR Journal of Nursing and Health Science. 5(3). Retrieved on 21-82016 from www.iosrjournals.org.

[9]. Lennart, O.S., Karim, M., Marianne, H \& Sten, A (2011) Awareness and Practice of testicular self examination. Nurse stand 26 (12) 51-52. Files Health

[10]. Mizie-Okoye M. M., Begam, H. I. \& Tella A. O (2016). Testicular Cancer Awareness and Testicular self-examination among senior secondary school students in Urban Local Government Area of Rivers State. Research Journali's Journal of Public Health 2(5) A pilot study. Retrieved on 7-10-2016. From http://www.researchgate.net/..BO38766.

[11]. Muliira J. K., Nalwanga P. B., Muliira R. S., \& Nakinga Z. (2012). Knowledge, perceived risk and barriers to testicular selfexamination among male university students in Uganda. Jmh 9(1) 36-44 Retrieved on 21-10-2016. From www.academia.edu/.../knowledge.

[12]. Ogundipe, S and Obinna, C (2008) why cancer is on the rise in the country, Vanguard Newspaper, Nigeria, report, http://allafrica.com/stories/200806170258.html

[13]. Onyiriuka A. N. \& Imoebe F. E. (2013). Testicular self-examination among Nigerian adolescent secondary school boys; knowledge, attitudes and practices. Retrieved on 7-10-2016 from https://www.researchgatenet/publication/15750775.

[14]. Ozturk A., Unalan A. \& Gulescr G. N. (2014). Knowledge, attitude and practices of technicians working at hospitals towards testicular cancer and self-examination of testicles in Turkey. Asian Pacific Journal of cancer prevention. Retrieved on 22-10-2016 from Dol:http://de.doiorg/10.7314/AP5C.2014.1q5.23.10095.

[15]. Peltzer K. \& Pengpid S. (2014). Knowledge, attitudes and practice of Testicular self-examination among male university students from Bangladesh, Madagascar, Singapore, South Africa and Turkey. Asian Pacific Journal of cancer prevention. Retrieved on 21-82016 from D01:http://dx.doi.org/10.7312/APJCP.2014.16.11.4741.

[16]. Ramim T., Mousavi, S. Q., Rosatmnia L., Basyar A., \& Ghanbari V. (2014). Student knowledge of Testicular cancer and selfexamination in a medical sciences University in Iran. Basic and Clinical Cancer research. 6(3). Retrieved on 22-10-2016 from www.bccrjournal.com.

[17]. Shallwani,K. Ramji, R. Ali, T.S,\& Khuwaja (2010) Self examination for breast and testicular cancers: a community based intervention study. Asian Pac J Cancer Prev, 11,383-386

[18]. Ugboma H. A \& Aburoma H. L. S. (2011). Public awareness of testicular cancer and testicular self-examination in academic environments: a cost opportunity. Retrieved on 8-10-2016 from http://www.scielo.br/scielorphp...

[19]. Ugurlu Z., Akkuzu G., Karahan A., Beder A., Dogan N., Okdems., \& Kav S. (2011). Testicular cancer awareness and testicular selfexamination among University students. Retrieved on 22-10-2016 from https://www.researchgate.net/.../5117925.

[20]. Vadaparampil S. T., Moser R. P., Loud J., Peters J. A., Greene M. H., \& Korde L. (2009). Factors associated with testicular selfexamination among unaffected men from multiple-case testicular cancer families. Retrieved 22-10-2016 from http://hapjournal.biomed.central.com/artricles/10.11 86/897-4287-7-11.

[21]. webMD (2016). Testicular Examination and Testicular self-examination (TSE). Retrieved on 21-9-2016 from www.webmd.com/men/guide/testicular-examination-and-testicular-self-examination-tse.

[22]. Yetisyigit T, Babacan N, Urun Y, et al (2014) Predictors of outcome of Patients with advanced non-seminomatous germ cell testicular Tumors. Asian Pac J cancer Prev 15 831-835 